\title{
A Preliminary Investigation of the Secondary Flame and Operational Properties of an Actively-valved Pulse Jet
}

\author{
Xuren Zhu ${ }^{1}$ Joel C. Lisanti ${ }^{2}$, Thibault F. Guiberti ${ }^{3}$, \\ and William L. Roberts ${ }^{4}$ \\ Clean Combustion Research Center \\ King Abdullah University of Science and Technology
}

Thuwal, 23955-6900, Saudi Arabia

\begin{abstract}
Due to their complex nature, a clear and comprehensive understanding of the mechanisms driving the combustion dynamics of pulse jets is not yet available. The present work intends to fill this gap by shedding some light on general operational properties of an active valve resonant pulse combustor as well as fundamental mechanisms. Pressure sensors and ion probes were used to quantify the global performance of the pulse combustor in naturallyaspirated mode or for different forced air flow-rates. It was shown that performance, here indicated by the pressure gain, improves when the forced air flow-rate increases. For a subset of operating conditions, infrared and thermocouple thermometry was used to measure side wall temperatures. Gas sampling was also used to infer species concentrations inside the combustor and along its main axis. These measurements highlighted the presence of a secondary flame located in the tail pipe, near the exhaust. A possible mechanism responsible for this secondary flame was proposed.
\end{abstract}

\section{Introduction}

The gas turbine engine is an integral part of the global energy infrastructure and, through widespread use, contributes significantly to the emission of harmful pollutants ( $\mathrm{NO}_{\mathrm{x}}$ and greenhouse gases). For this reason, there is great interest in improving the efficiency of these devices. However, after 80 years of development, current gas turbine technology is nearing its realizable efficiency limit and thus, using conventional approaches (increased pressure ratios, turbine inlet temperatures, and compressor efficiencies) only small future efficiency gains are possible at significant cost. Pressure gain combustion technologies have the potential to allow for a steep efficiency increase $[1,2]$ in these power generating devices. This can be achieved by replacing the pressure loss resulting from application of the isobaric heat addition process in conventional engines with a net gain in total pressure across the combustion chamber through the application of an isochoric combustion process.

Despite the important research effort that the detonation combustion based pressure gain combustion have drawn [35], the inefficiency caused by poor coupling between the detonation portion of the engine and the turbo machinery still possess a significant challenge. The high velocity of the detonation front (order of $\mathrm{km} / \mathrm{s}$ ) and the intrinsic high

\footnotetext{
${ }^{1}$ Postdoctoral Researcher, Mechanical Engineering, King Abdullah University of Science and Technology, Thuwal, 23955-6900, Saudi Arabia.

2 PhD Student, Mechanical Engineering, King Abdullah University of Science and Technology, Thuwal, 23955-6900, Saudi Arabia, AIAA Student Member

${ }^{3}$ Research Scientist, Mechanical Engineering, King Abdullah University of Science and Technology, Thuwal, 23955-6900, Saudi Arabia

${ }^{4}$ Director, Clean Combustion Research Center and Professor, Mechanical Engineering, King Abdullah University of Science and Technology, Thuwal, 23955-6900, Saudi Arabia, AIAA Senior Member
} 
unsteadiness property makes it extraordinarily difficult to implement into a gas turbine system [6]. Because of this, the deflagration based pulse combustion engine has gained significant attention from both industry and academia due to the considerable potential of high efficiency, low pollutant emission [1,7], and flexibility of implementation in real engine systems. However, according to the review work by Putnam et al [2] and Meng et al [8], limited knowledge has been achieved in understanding the complex dynamics and physical processes occurring in resonant pulse combustors. For instance, significant controversy exists in the autoignition mechanism of the fresh air/fuel mixture injected into the combustion chamber from cycle to cycle [9] leading to the necessity of further investigation.

Based on the inlet valve geometry, pulse combustors are usually classified into two categories, namely valveless [10, $11]$ and valved $[12,13]$. Recently, Lisanti and Roberts $[6,14,15]$ developed a novel actively valved pulse combustor with rotary valve for pressure gain combustion applications. The low mass passive valve was replaced with a ball shaped rotary valve allowing for much more durable operation. The performance and operational characteristics have been investigated with three operation modes identified and the resonant operation property quantified. The influence of heat release timing on the performance and operational characteristics has been further examined experimentally and numerically [15]. With the results, a general concept of the operational properties of the actively valved pulse combustor with gaseous fuel were understood.

In the previous work $[6,14,15]$ all of the data collection was focused on a single axial location so that the variation along the axial location and the global sense of the combustion/acoustic coupling have not been elucidated. However, the combustion information in the downstream of the combustor shows an identical influence in governing the operational performance of the combustor. For instance, regarding the operational principle of the Helmholtz-type pulse combustor, the recharge and compress process generated reversed flow of hot gases from the downstream may be one of the main reasons for the autoignition of fresh air/fuel mixture [8,14]. Another example can be found in the work by Geng at al. [16] and Anand et al. [9], in which it was shown that the unstable behavior of the amplitude fluctuation in the peak pressure of subsequent cycles in the combustion chamber was a function of the downstream flow characteristics. In this regard, investigation of the information of the whole pulse jet, especially far downstream, is desired to achieve the comprehension of the actively valve pulse combustor in a global sense thereby help to understand the complex physics and operational performance in pulse combustors.

In the present work, by virtue of the durable operation of the rotary actively-valved pulse jet, experiment will be performed to investigate the axially-distributed and time-averaged information of the combustor, with a particular focus on the tail pipe region. Through the results, a secondary flame generated close to the exit will be observed experimentally for the first time, to the best of our knowledge. The principle of its formation will then be discussed and the dependences of the preliminary properties on the operation conditions will be examined. Meanwhile, the general operational properties and the emission performance will be studied.

\section{Experimental Apparatus}

The experimental apparatus is composed of a pulse combustor, a DC motor with required interface and controls to drive the valve, a fuel/air supply system and sufficient instrumentation to characterize the performance of the combustor. An overview of the experimental apparatus used in this study is shown in Fig.1. The details of the experimental setup will be discussed in the following sections. 


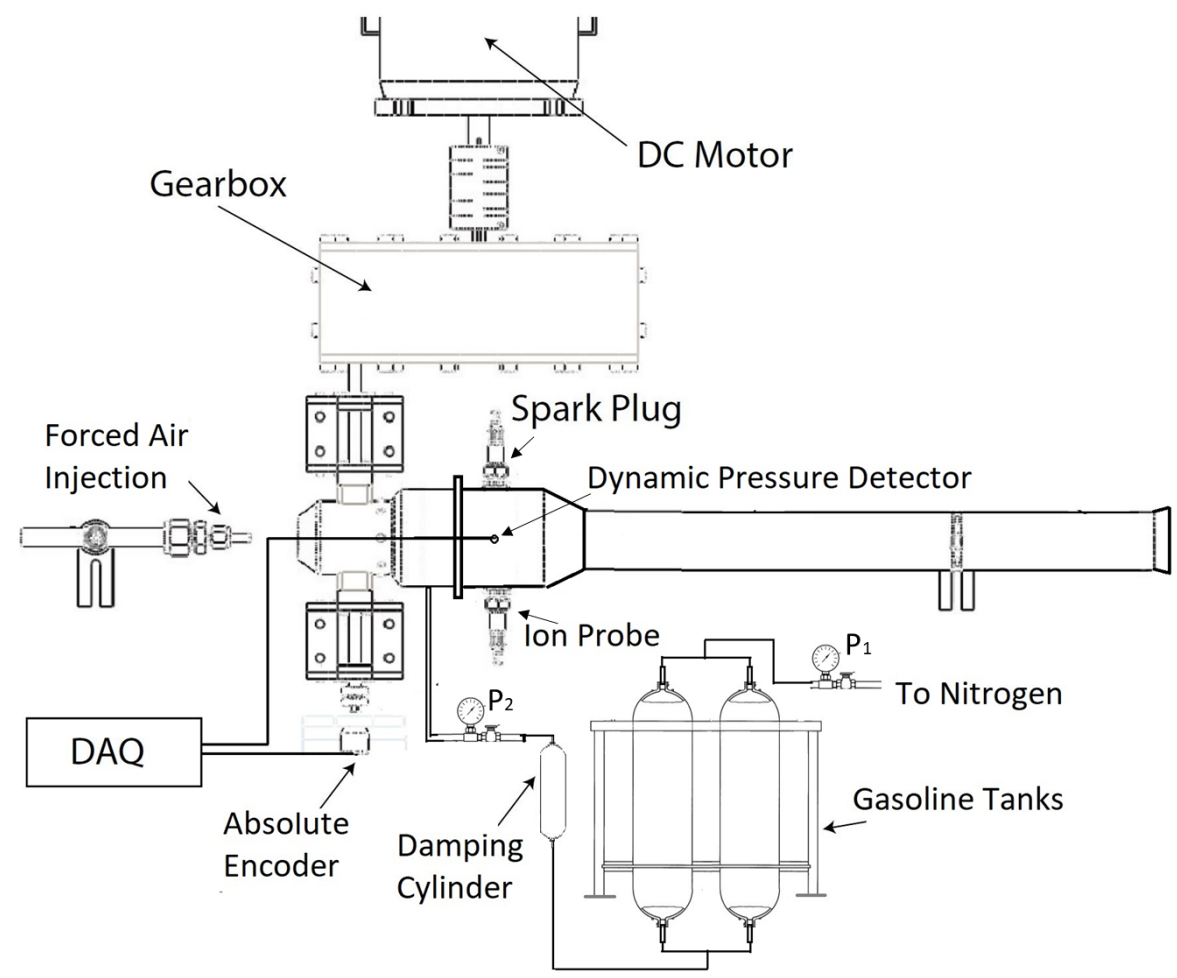

Fig.1 Schematic of the experimental system for testing the actively-valved pulse jet.

\section{A. Actively-valved pulse jet}

As it is seen in Fig.2 (a), the rotary actively-valved pulse jet is comprised of four sections, including the combustor head, combustion chamber, transition section, and tailpipe. The dimensions of each sections are also illustrated in the figure. The diameters of the combustion chamber and the tail pipe are $63.5 \mathrm{~mm}$ and $31.6 \mathrm{~mm}$, respectively. A tube is mounted on the combustion head allowing the fuel injection. The mechanical parts are fabricated from 304 stainless steel. The pulse jet used in the current work is similar to that in $[6,14]$. In Fig. 2 (b), the detailed structure of the combustor head is shown. One of the most important parts in the present actively-valved pulse jet is the rotary ball valve, featuring a round ball with a center cutting for allowing air flow passing through. The ball valve is driven by the DC motor so that it opens and closes periodically when rotating. The dimensions of the ball valve are also illustrated in Fig. 2 (b). Details of the actively-valved pulse jet are found in $[6,14]$.

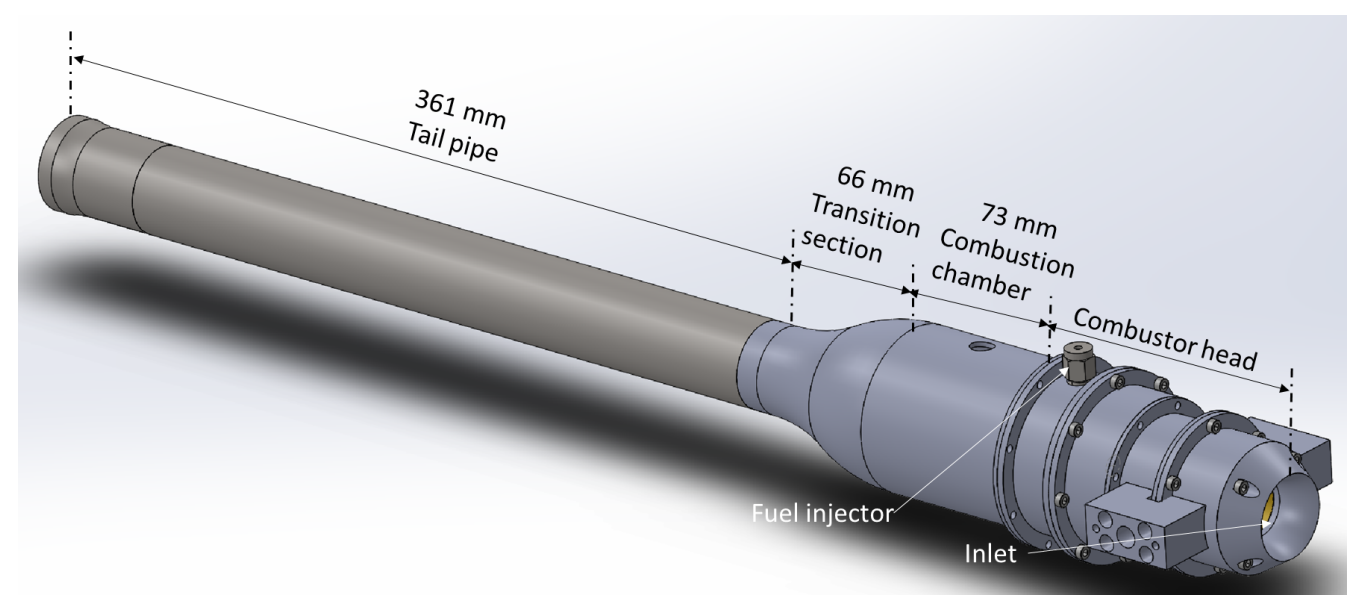


(a)

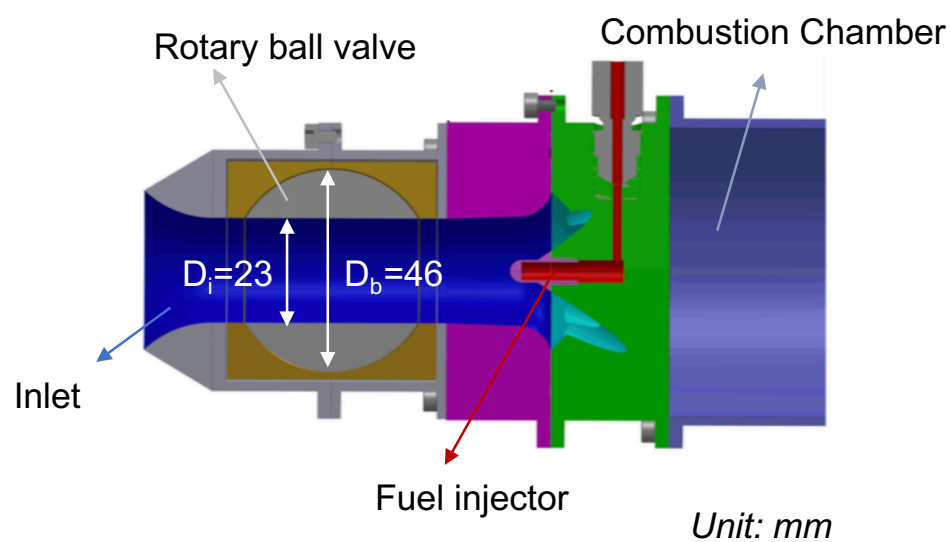

(b)

Fig. 2 Overview of the resonant pulse combustor design (a); sectional view of the combustor head (b).

\section{B. Fuel and air supply system}

Saudi Aramco fuels for advanced combustion engine (FACE-I) gasoline was used for fueling the pulse jet. The liquid gasoline is stored in the two tanks as seen in Fig. 1. In the upstream of the two tanks, high pressure nitrogen was connected so that a forced fuel injection is generated due to the pressure difference between the fuel tanks and the combustion chamber. To monitor pressure in the pipe lines, two pressure gauges $\left(\mathrm{P}_{1}\right.$ and $\left.\mathrm{P}_{2}\right)$ are installed as shown in Fig. 1. All the cases in the present work run under the same fuel flow-rate as the pressure at $\mathrm{P}_{1}$ is fixed to 5.5 bar and $\mathrm{P}_{2}$ to 2.0 bar. The ball valve rotation frequency is also fixed to $125 \mathrm{~Hz}$ so that it opens at the frequency of $250 \mathrm{~Hz}$ as the through hole on the ball valve opens twice when the ball rotates one cycle. To damp the pressure perturbation transferred from the combustion chamber due to unstable combustion, a damping cylinder is connected with the pipelines between the combustion chamber and fuel tanks. Fuel is continuously fed into the combustion chamber through a fuel nozzle with 4 small holes arranged uniformly on the nozzle tip. A forced air injector was placed in front of the pulse jet inlet. The forced air injection was used during the ignition procedure. During normal operation following the successful ignition of the pulse jet, the forced air flow can be maintained, or stopped to operate in naturally-aspirated mode.

\section{Measurement system}

The resonant pulse combustor was instrumented as follows. Dynamic pressure measurements of the combustion chamber were recorded with a Kistler (type 4049A) water cooled absolute pressure sensor paired with a Kistler (type 4665) amplifier. In order to maintain measurement fidelity at the highly elevated temperatures present during resonant operation, electronic thermal drift compensation was applied to the dynamic pressure transducer signal. The presence of a combustion front was detected with an ion probe mounted in the same plane of the pressure transducer. Details of the ion probe implementation can be found in a study by George et al. [17] as the described apparatus follows their methodology. The valve position was recorded by an absolute positioner connected to the ball valve through a shaft. Stagnation pressure were measured with KT-6-K-12-C Kiel probe mounted in the center of the exit-plane of the combustor exhaust. The measured results are transferred by an Omega PX2300-1BDI differential pressure transducer via a 1.2 meter 1/16 inch stainless steel tube. All instruments were recorded via a NI PICe-6363 high speed data acquisition (DAQ) device.

Gas sampling is carried out to infer emission characteristics at different axial locations. Samples are extracted through heated lines, and sent to a HORIBA Continues Emissions Monitoring (CEM) system. The CEM includes a THERMO (FID ES) analyzer coupled with a HORIBA (VS-E-3005) sample conditioning unit for measurement of unburned hydrocarbons (UHC), a HORIBA (VA-3022) Dual CLD analyzer for NO/NO2 measurement, and a HORIBA (VA-3116) analyzer for $\mathrm{CO} / \mathrm{CO} 2 / \mathrm{O} 2$ measurement. To measure gases concentration at different axial locations, a sampling probe with an outer diameter of $4 \mathrm{~mm}$ is inserted into the pulse jet from the exit of the tail pipe. The diameter ratio between the sampling probe and the tail pipe is small (about 0.12) so that there is no obvious influence observed on the measured dynamic pressure and ion signal results during sampling process. However, the limitation of the current sampling method is that there is no active cooling system applied to quench the chemistry in 
the sampling tube resulting in unknown measurement error. This problem will be solved in our near future work, in which a new sampling probe with water or aerodynamic cooling system will be used. Nevertheless, the measured gas emission result are not expected to affect the qualitative conclusions of the present work.

The external wall temperature was measured at different axial locations of the pulse jet with an infrared thermometer (Fisher Scientific). The measurement range of the thermometer is $-50-1000$ degrees centigrade. A thermocouple (type K) was also used complement these measurements.

\section{Results and discussion}

The following sections will discuss the experimental results with the focus on the generation of a secondary flame in the tail pipe section.

\section{A. General operational properties of the actively-valved pulse jet}

To understand the general idea of how does the actively-valved pulse jet operates, we first perform measurement of dynamic pressure and ion signal as a function of time. Results are shown in Fig. 3. The variations of the dynamic pressure and ion signal are denoted as black and red lines, respectively. The encoder signal was also captured to record the valve position as shown in Fig. 3. By examining Fig.3, an overview of the actively-valved pulse jet can be interpreted as follows. When the valve is opened (the blue line reaches the minimum value, e.g. at $t=3.005 \mathrm{~s}$ ), pressure in the combustion chamber takes a value lower than atmospheric so that the air in the surrounding will be entrained into the pulse jet. This process stops when the valve closes, meanwhile the combustion chamber reaches the peak pressure. The fuel/air mixture is then ignited by the resident hot gases of the previous cycle or by the heat transfer from the hot wall. The combustion event generates ions that are detected by the ion probe thereby resulting in a sudden drop of the ion signal as shown in Fig. 3. After combustion, the after burning gases expand and discharge through the exhaust tube. Due to the momentum effect of the expanding gases, the combustion chamber pressure keeps decreasing until the reaches the lowest value, which is smaller than that in the atmosphere. At this point, a full pulse jet cycle finishes, and fresh air entrainment and another new cycle starts.

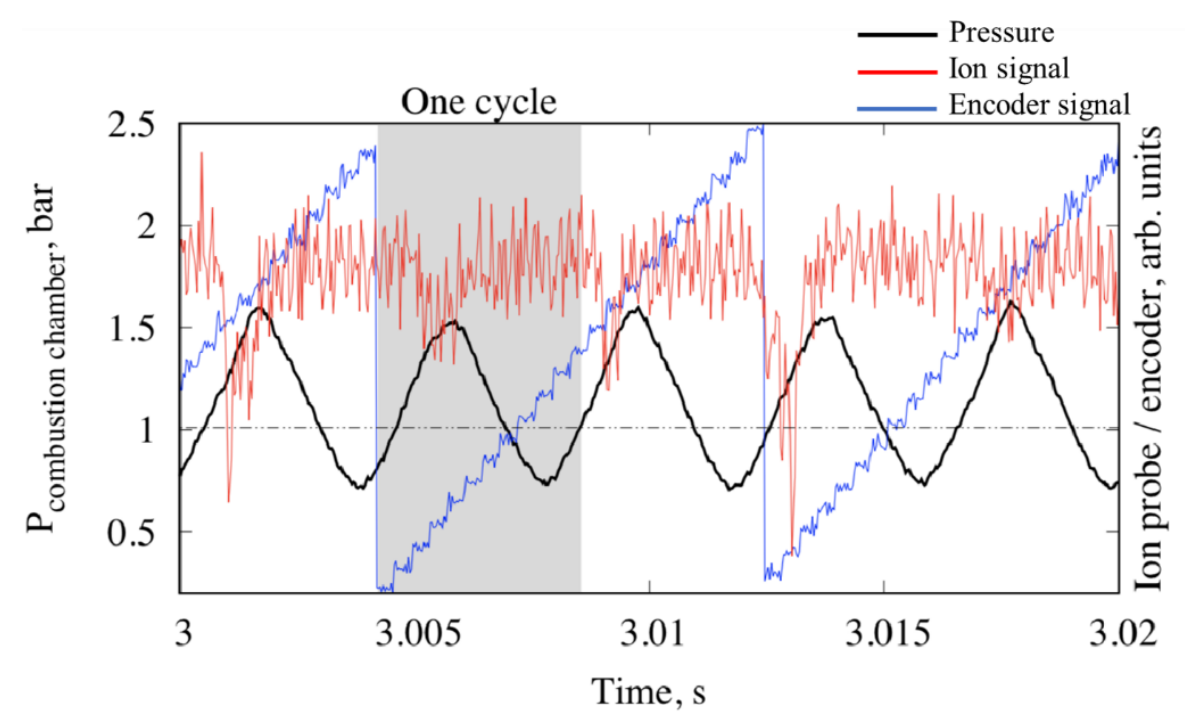

Fig. 3 Time variation of pressure (black line), ion signal (red line), and encoder signal (blue line)

\section{B. Wall temperature distribution as a function of axial locations}

Infrared thermometer was used to measure the time-averaged wall temperature for the normally-aspirated condition, i.e., without forced air injection. Each measurement lasted at least 1 minute to obtain the time-averaged wall temperature. To confirm the fidelity of the infrared thermometer results, thermocouples were also used and comparisons exhibit small differences $(<30 \mathrm{~K})$. In Fig. 4, the axial location at $0 \mathrm{~mm}$ is the solid wall located between the combustion chamber and the combustor head, whilst the axial location at $500 \mathrm{~mm}$ is the exit of the exhaust pipe. 
Starting from $0 \mathrm{~mm}$, wall temperature keeps increasing until peaks at $70-130 \mathrm{~mm}$, where the transition section of the pulse jet is located. This can be interpreted as follows. The mixing process of fresh air/fuel and the hot products mainly happens in the region close to the inlet of the combustion chamber $(0-60 \mathrm{~mm})$. Additionally, the cold fuel/air mixture injected directly towards the wall of this section so that wall temperature is relatively low compared to that of other locations in the combustion chamber. After a specific distance away from the combustor inlet, fresh air/fuel mixture has mixed well with the resident hot products and auto-ignition occurs. As the result of combustion, wall temperature increases due to the heat transfers. The peak wall temperature located at the transition section indicates that the heat transfer from the hot products to the wall is the largest at this position, where the existence of convergence causes a gradually decreased sectional area so that the flow velocity is increased. The increased velocity therefore reinforces the convective heat transfer.

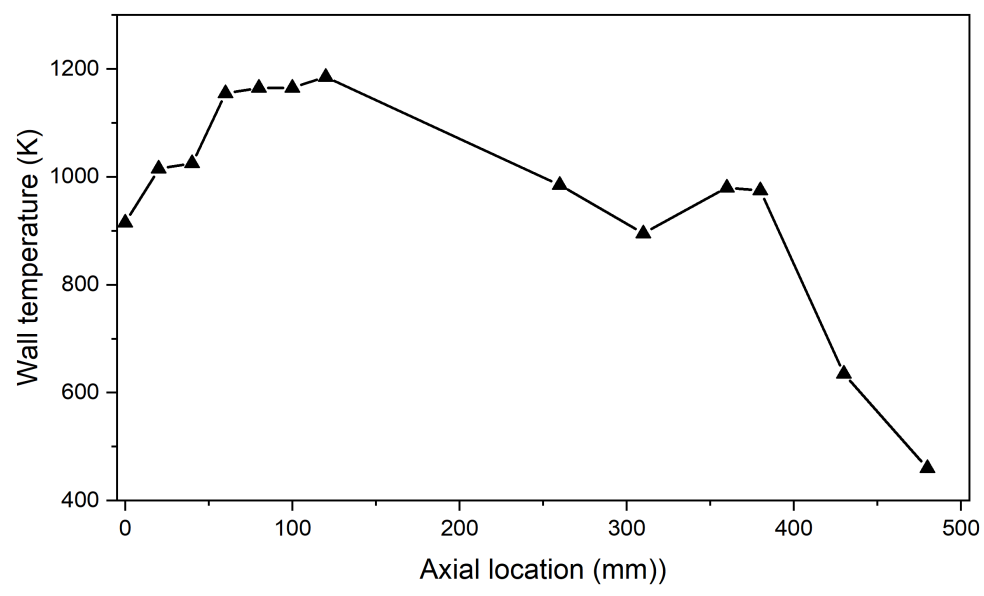

Fig. 4 Time-averaged wall temperature as a function axial location of the pulse jet

In the tail pipe (140-500 mm), the wall temperature keeps decreasing with axial location as the result of heat loss to environment and the lack of heat source. This trend stops at around $380 \mathrm{~mm}$, where a sudden temperature rise is observed. Surprisingly, the temperature of this hot spot reaches a remarkably high value of around $900 \mathrm{~K}$, which is close to the wall temperature of the combustion chamber. A possible explanation is that a new heat source exists at this downstream location, that heats up the wall. This possibility is corroborated by the simulations of Geng et al [16]. In their work, it was found that some unburnt fuel exists in the combustion chamber near the wall region, where the oxygen concentration is very low. Unburnt fuel is then convected downstream towards the tail pipe. Recalling the discussion above about the operation principle of pulse jet, fresh air is inhaled into the combustor from environment through the exit thereby there is a chance to have a reaction between the unburnt fuel and the oncoming reversed air flow under appropriate conditions, e.g. high temperature and suitable fuel/oxidizer ratio. Further details will be discussed in the later sections. In Fig. 4, it is evident that due to existence of the reversed cold air flow from the exit, wall temperature drops much faster at locations $380 \mathrm{~mm}-500 \mathrm{~mm}$ than upstream of the tail pipe. 


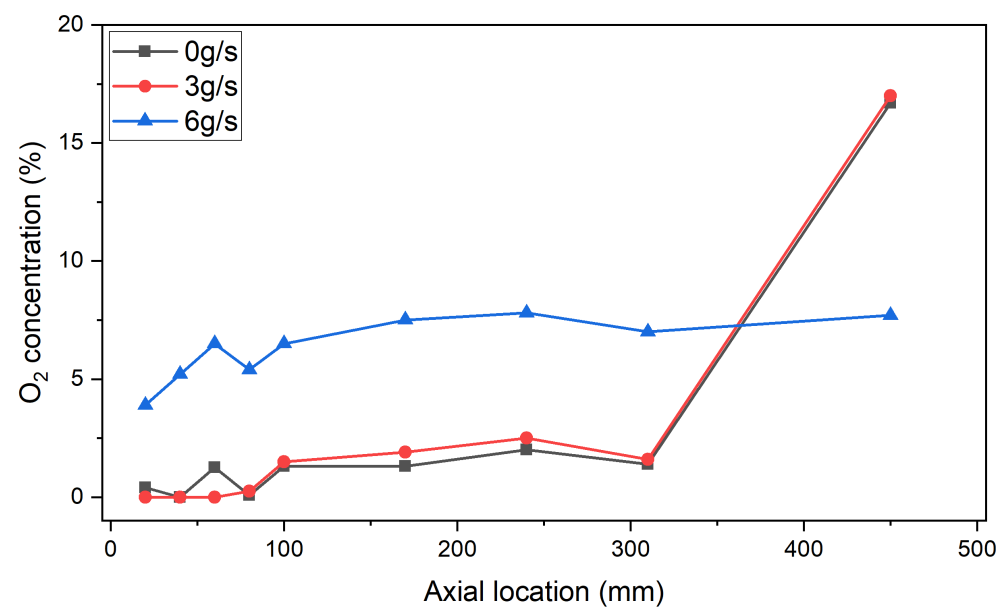

(a)

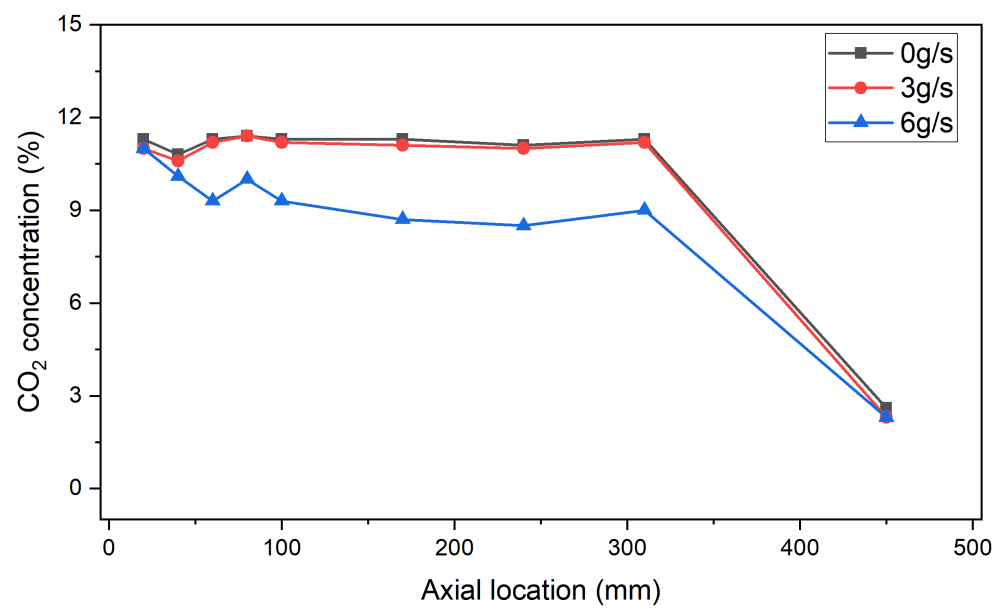

(b)

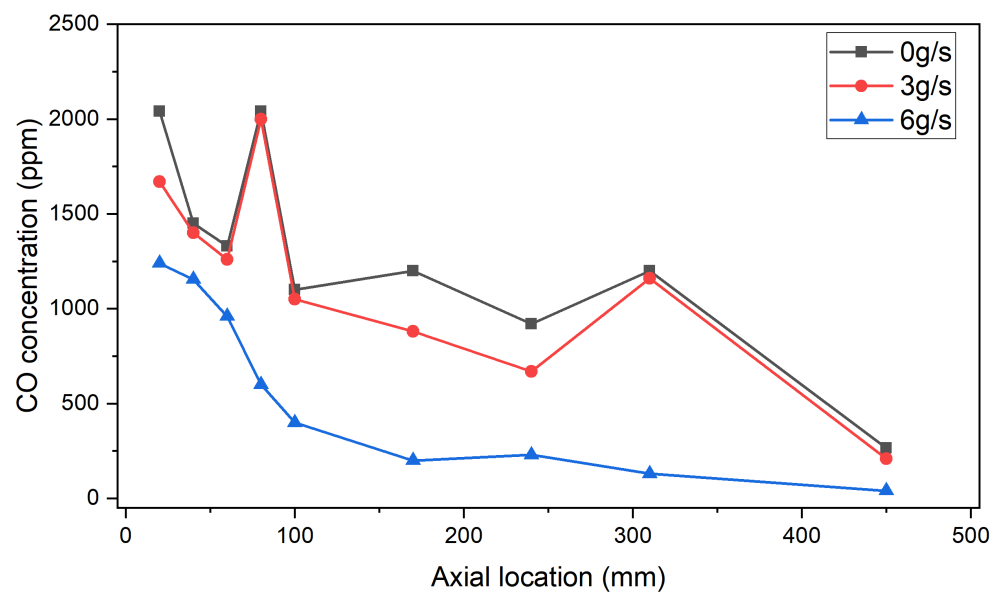

(c)

Fig. 5 (a) oxygen; (b) $\mathrm{CO} 2$; (c) $\mathrm{CO}$ concentration at the center line as a function of axial location. 


\section{Gas sampling}

To provide more solid evidence to support the existence of a secondary flame in the tail pipe, we have measured gas emission along the center line at different axial locations of the pulse jet. Fig.5 (a)-(c) show the concentrations of $\mathrm{O}_{2}, \mathrm{CO}_{2}$ and $\mathrm{CO}$. Three different forced air flow rates, i.e. $0 \mathrm{~g} / \mathrm{s}, 3 \mathrm{~g} / \mathrm{s}$ and $6 \mathrm{~g} / \mathrm{s}$, were used with the corresponding results marked by different colors in Fig. 5. A non-monotonic trend for the gases emission is observed for the axial locations $0-140 \mathrm{~mm}$. This indicates that the behavior in the combustion chamber and transition section is rather complicated. The most intense combustion event in the combustion chamber may occurs at around $80 \mathrm{~mm}$ as such an obvious drop in $\mathrm{O}_{2}$ concentration and rise in $\mathrm{CO}_{2}$ concentration are observed, except for the forced air flow-rate of $6 \mathrm{~g} / \mathrm{s}$. In the tail pipe, gas concentrations change gradually until some location where the $\mathrm{O}_{2}$ concentration increases and the $\mathrm{CO}_{2}$ concentration decreases. The steep change of $\mathrm{O}_{2}$ and $\mathrm{CO}_{2}$ concentrations in the region close to the exit is mainly due to the dilution effect of the reversed air flow injection from the atmosphere.

Similar trend is observed in Fig. 5 (c) for $\mathrm{CO}$ concentration, whereas a sudden increase then decrease is observed at $320 \mathrm{~mm}$. This sudden change can be treated as an evidence of the presence of a secondary flame in the tail pipe, immediately followed by dilution with reverse-flow air. Note that the change in the $\mathrm{O}_{2}$ and $\mathrm{CO}_{2}$ concentration is not as obvious at $320 \mathrm{~mm}$. This could be explained by the fact that the secondary flame may be rather weak and not strong enough to modify significantly the concentrations of the main species. Nevertheless, a slight decrease in $\mathrm{O}_{2}$ concentration and increase in $\mathrm{CO}_{2}$ are also observed at around $320 \mathrm{~mm}$ in Fig. 5 (a) and (b), respectively. This unexpected trend again confirms that there is a secondary flame existing somewhere around $300-400 \mathrm{~mm}$. The influence of forced air injection is also shown in Fig. 5. No evident difference is observed between $0 \mathrm{~g} / \mathrm{s}$ and $3 \mathrm{~g} / \mathrm{s}$ of forced air. When the forced air flow-rate is further increased to $6 \mathrm{~g} / \mathrm{s}$, the pulse jet operates leaner, hence higher $\mathrm{O}_{2}$ concentrations and lower $\mathrm{CO}_{2}$ and $\mathrm{CO}$ concentrations.

The unburnt hydrocarbon (UHC) concentration along the center line of the pulse jet is shown in Fig. 6. Regardless of the forced air flow-rate, negligible UHC concentrations are observed in the tail pipe. Because measurements discussed above demonstrated the presence of a secondary flame, this suggests that the unburnt fuel mainly exists in the near wall region and is not detected by the sampling probe which is placed on the center line of the pulse jet. Examining the UHC concentration in the combustion chamber (0-60 $\mathrm{mm}$ in Fig. 6), a steep increase followed by a decrease is found for the two cases with lower forced air injection $(0$ and $3 \mathrm{~g} / \mathrm{s})$. Increasing the forced air flow rate to $6 \mathrm{~g} / \mathrm{s}$, there is abundant oxygen in the combustion chamber so that the UHC is very low as it is rapidly consumed in the flame.

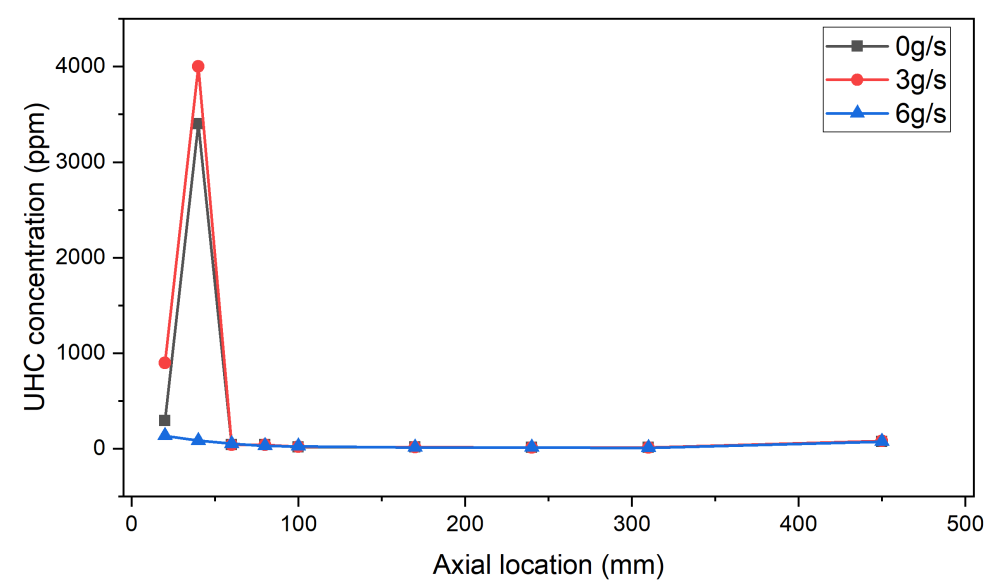

Fig. 6 Unburnt hydrocarbon concentration at the center line as a function of axial location

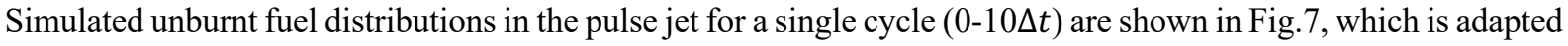
from the work by Geng et al [16]. Based on the above measurements and aided by the numerical simulations of [16] (shown Fig. 7), the following mechanism can be proposed to explain how is the secondary flame generated. At $t=0$ of Fig. 7, a large quantity of fuel is found in the near wall region of the combustion chamber as denoted by the black contour. After a specific time period (e.g. at $4 \Delta t$ ), most of the fuel has been consumed but a small portion of fuel remains unburnt and is convected downstream. The unburnt fuel remains in the near wall region until $t=6 \Delta t$, at which time the reversed air flow from the atmosphere starts to be entrained into the tail pipe and fuel in the tail pipe can be 
seen away from the wall. The entrained air flow plays two roles, first it supplies fresh oxidizer for combustion; second it causes a flow disturbance so that the unburnt fuel is transported towards the center line where it mixes with the air and hot products. The mixture then ignites to produce a secondary flame in the tail pipe. There are additional clues proving the existence of a secondary flame in Fig. 7. One is that the small portion of unburnt fuel disappears at $t=2 \Delta t$ and never exhausts through the tail pipe. There must be a combustion event happening somewhere in the tail pipe to consume the unburnt fuel.

As shown in Fig.7, the residence time of the UHC at a specific location of the tail pipe is very short and most of the fuel has been consumed in the combustion chamber. This could be the possible reason for that the measured averaged UHC value shown in Fig. 6 is very small.

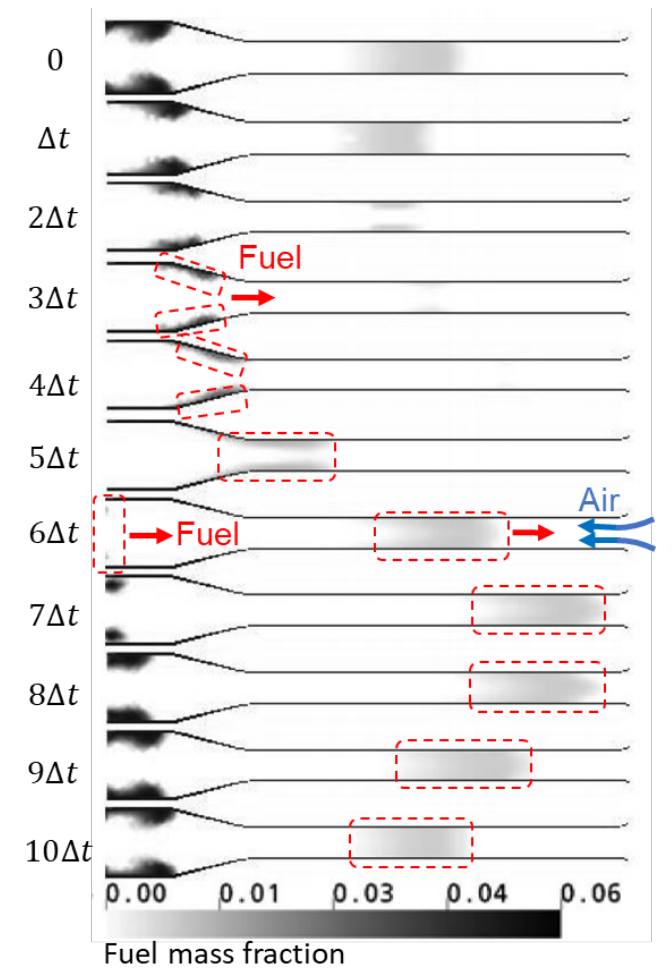

Fig. 7 Fuel mass fraction in a pulse jet (adapted from Geng et al [16] with the permission of the authors)

\section{Pressure gain and emission performance}

The pressure gains measured in the pulse jet for different flow rates of forced air are shown in Fig. 8. With this actively-valved pulse jet, positive pressure gain has been achieved in all cases. The pressure gain performance globally increases with the forced air flow-rate. 


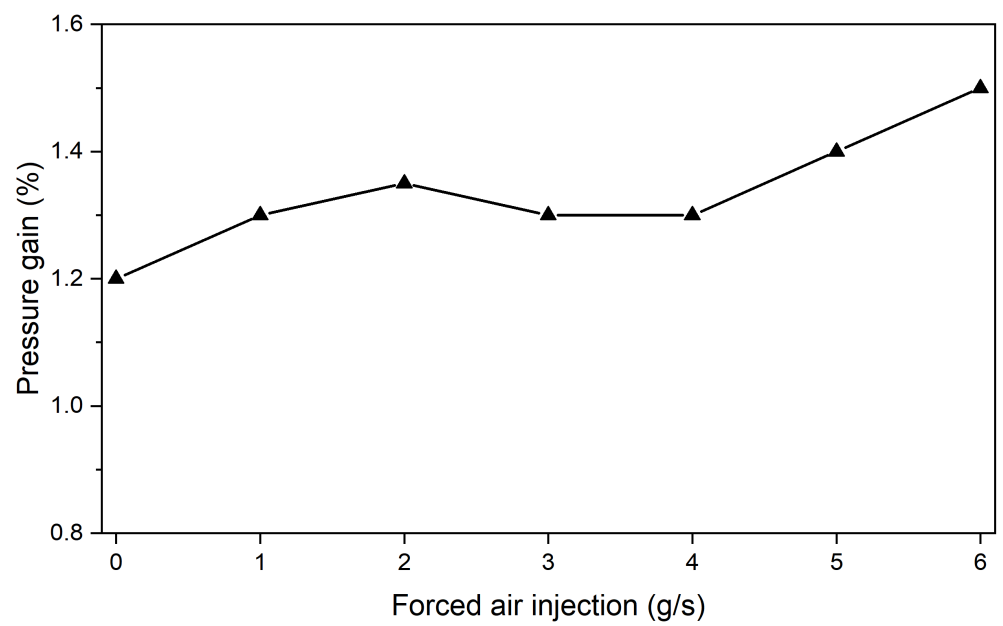

Fig. 8 Pressure gain as a function of the flow rate of the forced air.

The NOx concentration measured along the center line is plotted in Fig. 9 as a function of axial location. Similar to $\mathrm{CO}$ in Fig. 5 (c), the monotonic trend in the combustion chamber and transition section indicates the complexity of the flow and combustion processes in the combustion chamber. In the tail pipe, an obvious increase of NOx concentration is observed at $320 \mathrm{~mm}$ for the cases with forced air flow-rates of $0 \mathrm{~g} / \mathrm{s}$ and $3 \mathrm{~g} / \mathrm{s}$. The increase can be again attributed to the existence of a secondary flame. Overall, the NOx concentration in the tail pipe before dilution with reverse flow air is low $(<120 \mathrm{ppm})$ indicating a good emission performance of this actively-valved pulse jet. Further increasing the forced air flow-rate to $6 \mathrm{~g} / \mathrm{s}$, the NOx concentration is reduced dramatically to a very low level (around $30 \mathrm{ppm}$ ) while the pressure gain remains large (see Fig. 8). This shows that forced air plays an important role in affecting the overall performance of the pulse jet and this will be investigated further in the future.

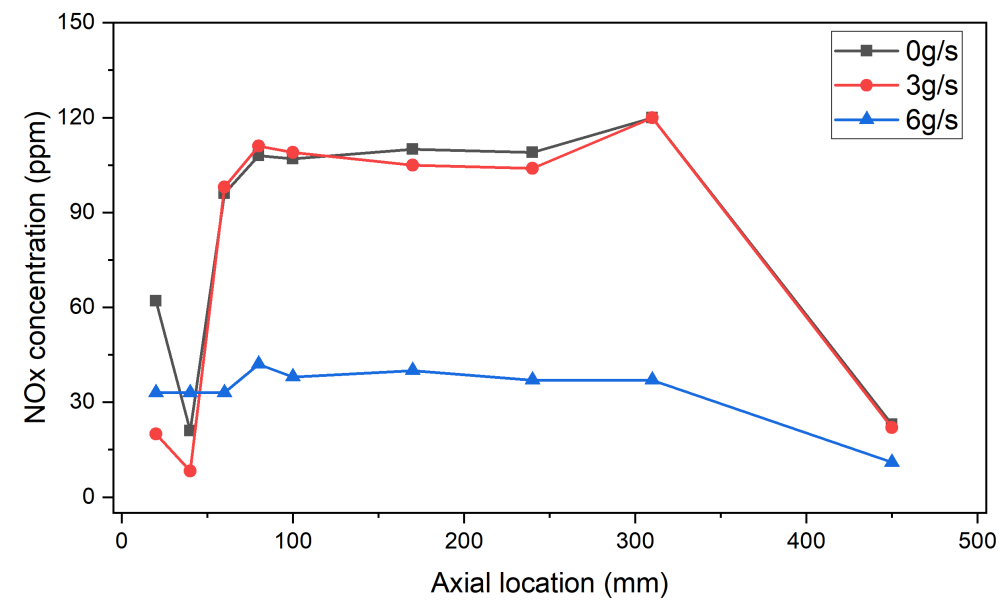

Fig. 9 NOx concentration at the center line as a function of axial location.

\section{Conclusion remarks}

In the present work, the general operational property and performance of an actively-valved pulse jet has been examined experimentally for a fixed valve rotation frequency and fuel flow rate, but for varied forced air flow-rates. Wall temperature and gas concentration measurements show that a secondary flame exists downstream of the combustion chamber, in the tail pipe of the pulse jet. Aided by simulations published earlier by Geng et al [16], the mechanism generating this secondary flame can be described as follows:

1. The formation of the secondary flame is due to the interaction between the unburnt fuel coming from combustion chamber and the fresh air entrained through the exhaust by a reverse flow. 
2. The unburnt fuel travels in the near wall region, where the oxygen concentration is low, hence survives until a specific location where the reversed fresh air flow can reach.

The forced air flow-rate has a large influence on the pressure gain and exhaust emissions. Globally, increasing the forced air flow-rate improves performances.

Further investigations, especially improved measurement of gas concentrations, are necessary to provide more comprehensive and solid evidences and elucidate the current observations.

\section{Acknowledgments}

The research reported in this publication was supported by funding from King Abdullah University of Science and Technology (KAUST), under award number BAS/1/1370-01-01.

\section{References}

[1] Paxson, D. E., and Kaemming, T., "Influence of Unsteadiness on the Analysis of Pressure Gain Combustion Devices," Journal of Propulsion and Power, Vol. 2, No. 30, 2014, pp. 377-383.

[2] Bellest, F. E., and Kentfield, J. A. C., "Pulse Combustion" Progress in Energy and Combustion Science, Vol. 12, No. 1,1986, pp. 43-79.

[3] Ma, F., Choi, J.-Y., and Yang, V., "Propulsive performance of air breathing pulse detonation engines," Journal of Propulsion and Power, Vol. 22, No. 6, 2006, pp. 1188-1203.

[4] Allgood, D., Gutmark, E., Hoke, J., Bradley, R., and Schauer, F., "Performance measurements of multicycle pulse-detonation engine exhaust nozzles," Journal of Propulsion and Power, Vol. 22, No. 1, 2006, pp. 70-779.

[5] Harris, P. G., Ripley, R., and Guzik, S., "Pulse detonation engine as a ramjet replacement," Journal of Propulsion and Power, Vol. 22, No. 2, 2006, pp. 462-473.

[6] Lisanti, J. C., and Roberts, W. L., "Pulse Combustor Driven Pressure Gain Combustion for High Efficiency Gas Turbine Engines," Combustion for Power Generation and Transportation, Springer, 2017, pp. 127-152.

[7] Zinn, B. T., "Pulse combustion: recent applications and research issues," Symposium (International) on Combustion, Vol. 24, 1992, pp. 1297-1305.

[8] Meng, X., de Jong, W., and Kudra, T., "A state-of-the-art review of pulse combustion: principles, modeling, applications and R\&D issues," Renewable and Sustainable Energy Reviews, Vol. 55, 2016, pp. 73-114.

[9] Anand, V., Jodele, J., Knight, E., Prisell, E., Lyrsell, O., and Gutmark, E., "Dependence of Pressure, Combustion and Frequency Characteristics on Valved Pulsejet Combustor Geometries," Flow, Turbulence and Combustion, Vol. 100, No. 3, 2017, pp 829-848.

[10] Kentfield, J. A. C., and Fernandes, L. C. V., "Improvements to the Performance of a Prototype Pulse , PressureGain, Gas Turbine Combustor," Journal of engineering for Gas Turbines and Power, Vol. 112, No. 1, 1990, pp. $67-72$.

[11] Kentfield, J. C., "The Shrouding of Highly Loaded, Aerovalved, Pulse, Pressure-Gain Combustors," Combustion Science and Technology, Vol. 94, No. 1-6, 1993. pp 25-42.

[12] Muller, J. L., "Theoretical and Practical Aspects of the Application of Resonant Combustion Chambers in Gas Turbines," Journal of Mechaanical Engineering Science, Vol. 13, No. 3, 1971, pp. 137-150.

[13] Paxson, D. E., and Dougherty, K., "Ejector Enhanced Pulsejet Based Pressure Gain Combustors: An Old Idea With a New Twist," 41st AIAA/ASME/SAE/ASEE Joint Propulsion Conference \& Exhibit, AIAA, Tucson, Arizona, 2005.

[14] Lisanti, J. C., and Roberts, W. L., "Design of an actively valved and acoustically resonant pulse combustor for pressure-gain combustion applications," 54th AIAA Aerospace Sciences Meeting, San Diego, California, 2016,

[15] Lisanti, J. C., and Roberts, W. L., "Influence of Actively Controlled Heat Release Timing on the Performance and Operational Characteristics of a Rotary Valve, Acoustically Resonant Pulse Combustor," 55th AIAA Aerospace Sciences Meeting, , Grapevine, Texas 2017.

[16] Geng, T., Kiker, A., Ordon, R., Kuznetsov, A., Zeng, T., and Roberts, W., "Combined numerical and experimental investigation of a hobby-scale pulsejet," Journal of propulsion and power, Vol. 23, No. 1, 2007, pp. $186-193$.

[17] St. George, A. C., Driscoll, R. B., Munday, D. E., and Gutmark, E. J., "Development of a rotating detonation engine facility at the University of Cincinnati," 53rd AIAA Aerospace Sciences Meeting, Kissimmee, Florid 2015 . 